RESEARCH ARTICLE

\title{
Identification of drought prone agro-ecological regions in Sri Lanka
}

\author{
R.D. Chithranayana* and B.V.R. Punyawardena \\ Natural Resource Management Centre, Department of Agriculture, No.5 Sarasavi Mawatha, Peradeniya.
}

\begin{abstract}
Drought occurrences are inevitable in almost all regions of Sri Lanka. This study has attempted to identify the agro-ecological regions (AERs) which are vulnerable to drought conditions during Maha and Yala seasons, using a drought index based on the monthly Moisture Availability Index (MAI).

The Wet Zone does not exhibit droughts during Maha seasons except WL2b and WL3 regions which have a slight vulnerability for droughts. All AERs in the Up country and Mid country Intermediate Zone are generally free from droughts. All AERs of the Low country Intermediate Zone are vulnerable to drought during Maha seasons except IL2 and IL1c. In Yala seasons, frequency of drought occurrence in the Wet Zone is low. The drought proneness of the Intermediate Zone is relatively higher compared to the wetter part of the island. All AERs in the Low country Intermediate Zone are vulnerable to droughts except the IL1a region. Excluding the AERs that adjoin the high rainfall receiving AERs of the Wet Zone, all other AERs of the Mid country Intermediate Zone are also prone to droughts. Almost all AERs of the up country Intermediate zone are less likely to experience droughts. All AERs of the Dry Zone are highly vulnerable to droughts. In contrast to Yala seasons, almost all AERs of the Dry Zone are less likely to experience droughts during Maha seasons except those located in the extreme northwestern and southeastern regions.
\end{abstract}

Keywords: Agro-ecological regions, drought, rainfall, Sri Lanka

\section{INTRODUCTION}

Agro-ecology has an important role to play in designing and evaluating agricultural research, land use and other development strategies ${ }^{1}$. In recognition of this potential, Sri Lanka was delineated into 24 agro-ecological regions, (AERs) in 1975 which were subsequently revised in
2003 to identify 46 AERs (Figure 1). Even though each AER represents a particular combination of natural characteristics of climate, soil and relief ${ }^{2}$ and rainfall in particular, the degree of vulnerability of each region to drought conditions cannot be readily incurred from the map. The Disaster Management Act No. 13, 2005 of the Government of Sri Lanka has identified 21 natural or man-made disasters in Sri Lanka and drought is the most frequent disaster listed. Droughts or extreme negative rainfall anomalies are experienced in Sri Lanka under three major meteorological situations. One situation arises during the northeast monsoon season (December to February) when the air stream over the island comes from a Northern hemisphere high-pressure system and travels over the dry mainland of India immediately before reaching Sri Lanka. Marked decreases in formation of weather systems (low-level disturbances, depressions and cyclones) in the Bay of Bengal also creates below normal rainfall during October to January. The resulting droughts and dry spells can affect most regions of the island. Rainfall during mid March to early May is generally due to convection under local thermal conditions and influence of the Inter-Tropical Convergence Zone (ITCZ). However, activity of the ITCZ during this period is highly variable and thus, it is common to experience below normal rainfall in most regions of the country, especially in the Dry Zone. The third situation may occur during the southwest monsoon months of May to September when the prevailing monsoon air stream is relatively dry due to deviation of flow direction from its usual path. Under such situations, dry conditions are likely to occur in agro-ecological regions that lie across even the Wet and Intermediate Zones. Thus, it is apparent that almost all regions of the island have a potential threat of drought. Historical and legendary accounts show that even the wettest region 
of the country, the southwestern part of the central hills have had severe droughts in the past ${ }^{3}$. However, drought mitigation efforts during the last century have been non-systematic, without committed drought-planning programmes, and main emphasis has been placed on short term solutions (i.e. emergency relief). There has been no focus on long term strategies for appropriate land and crop management practices as well as socio-economic issues. This is mainly due to the lack of clear understanding on spatial and temporal variability of droughts in Sri Lanka. If such studies have been undertaken, the impacts of large rainfall deficits could have been minimized while avoiding the impacts of less extreme rainfall deficits. Hence, this study was undertaken to evaluate the drought proneness of the AERs during the main growing seasons, namely, Yala (March - August) and Maha (September to February).

\section{METHODS AND MATERIALS}

Negative anomaly of rainfall is the most widely used parameter to identify drought conditions in an area. However, vulnerability of an area to drought conditions also depends on the atmospheric demand for water or more specifically, evapotranspiration. This applies very much to agricultural drought where crop production is a function of soil moisture adequacy, which in turn depends on the rainfall and evapotranspiration. Moisture Availability Index (MAI) relates soil moisture adequacy for crop growth ${ }^{4}$.

Moisture Availability Index (MAI): MAI is the ratio of the Dependable Rainfall (DRF) to Potential Evapotsranspiration (PET) where dependable rainfall is the amount of rainfall of a particular location at 75 percent probability or expectancy level. It is the rainfall that could be expected to occur at least during 75 years out of 100 years.

\section{$\mathrm{MAI}=\mathrm{DRF} / \mathrm{PET}$}

A value of MAI less than or equal to 0.33 is considered as a very dry condition and not at all suited

Table 1: Drought severity classification

\begin{tabular}{cl}
\hline $\begin{array}{c}\text { No. of months with MAI less } \\
\text { than or equal to } 0.34\end{array}$ & Drought severity \\
\hline 0 & wet \\
1 & slightly wet \\
2 & mild drought \\
3 & drought \\
4 or more & severe drought \\
\end{tabular}

for rainfed agriculture ${ }^{5}$. Hence, any month having a MAI value of less than or equal to 0.33 could be considered as a dry month. In this study, monthly MAI values for each agro-ecological region were calculated using monthly DRF values ${ }^{6}$ and PET data for the same locations were obtained from relevant published information ${ }^{7}$. Table 1 shows the drought severity classification adopted in this study to identify the drought prone AERs during Yala and Maha seasons. The Yala season constitutes of six months from March to August while six months from September to February are considered as the Maha season. The drought severity classification assumes that stored soil moisture is adequate to supply the water requirement of crops for three weeks or more and that short drought periods are of lesser importance.

\section{RESULTS AND DISCUSSION}

\section{Spatial pattern of drought during Maha season}

Generally, the second intermonsoon rains of any year exhibits less spatial and temporal variability and the drought conditions during Maha seasons is mainly attributed to the spatial and temporal variability of northeast monsoon rains.

All the AERs in the Up country Wet Zone are free from drought hazards during Maha seasons due to the relatively high effectiveness of northeast monsoon rains over those regions (Table $2 \&$ Figure 2). Among the six AERs in the Mid country Wet Zone only two regions, namely, WM2b and WM3a are prone to mild drought conditions while the rest are free from drought hazards during Maha seasons.

The situation is slightly different in the Low country Wet Zone where two AERs, namely, WL2b and WL3 are prone to mild drought conditions while the other three AERs are unlikely to experience drought conditions during Maha seasons. As both WL2b and WL3, are located further away from the central hills, the contribution of rains from the northeast monsoon and its associated weather systems in the Bay of Bengal is minimal. Therefore, both January and February are dry months in these regions. Since these two months are at the end of the Maha season and exhibit only mild drought conditions, occurrence of severe drought injuries to the crops are unlikely. Meanwhile, regular occurrence of periods of drought in these two regions during January and February favour the tree fruit crop cultivation (i.e, Rambutan) which requires a dry spell of critical length for flower primodia initiation. 


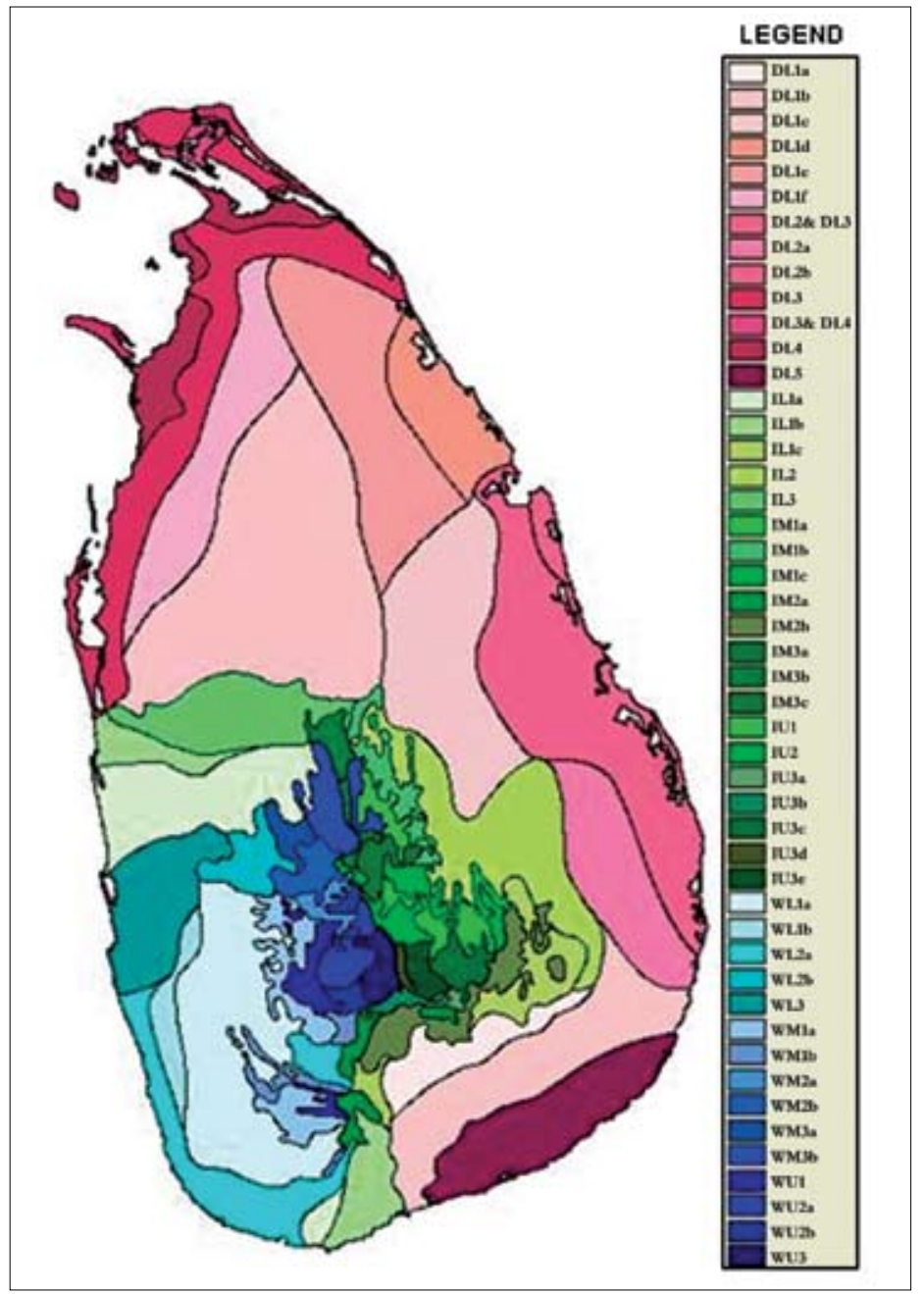

Figure 1: Agro-ecological regions of Sri Lanka ${ }^{6}$

In the case of the Intermediate Zone, all AERs in both the Up country and Mid country Intermediate Zone are generally free from drought hazards during Maha seasons (Table $2 \&$ Figure 2). This is mainly due to the relatively high effectiveness of the northeast monsoon rains over these regions as they lie in the eastern flanks of the central highlands.

Out of the five AERs of the Low country Intermediate Zone, two AERs, namely, IL2 and IL1c are free from drought hazards during Maha seasons. As these two regions lie in the Wellassa region, the foothills of eastern flanks of central highlands, they receive abundant rainfall from northeast monsoon rains up to February and exhibit no droughts during normal Maha seasons. As the name "Wellassa" implies, there had been hundreds of thousands of paddy fields in this region during ancient times. It suggests that droughts were a rare event in this region even in the past. If not, early settlers would not have cultivated such a vast extent of paddy in this region. Even at present, farmers in these regions have terraced the highlands for paddy cultivation during Maha season to harness the potential of the extended nature of Maha rains up to February and their certainty. Meanwhile, the other three AERs of the Low country Intermediate Zone, namely, IL1a, IL1b and IL3 which lie in the western half of the island has mild drought conditions during Maha seasons due to relatively lower contribution of rains from the northeast monsoon and its associated weather systems in the Bay of Bengal.

In the Dry Zone, all the AERs of the Alfisol region has slightly wet conditions during Maha seasons except DL1f region (Table $2 \&$ Figure 2). Being farther away from the effective region of the northeast monsoon, the DL1 f region is somewhat vulnerable to drought conditions during Maha seasons (Mild drought). DL3 adjacent to DL1f, also exhibits similar situation during Maha seasons. 
Table 2: Monthly drought severity of each AER during the Maha season

\begin{tabular}{|c|c|c|c|c|c|c|c|}
\hline \multirow[t]{2}{*}{ Zone } & \multicolumn{6}{|c|}{ Maha } & \multirow{2}{*}{$\begin{array}{c}\text { Severity } \\
\text { Class }\end{array}$} \\
\hline & Sep & Oct & Nov & Dec & Jan & Feb & \\
\hline \multicolumn{7}{|l|}{ WU1 } & $\mathrm{w}$ \\
\hline \multicolumn{7}{|l|}{ WU2a } & $\mathrm{W}$ \\
\hline \multicolumn{7}{|l|}{ WU2b } & $\mathrm{w}$ \\
\hline \multicolumn{7}{|l|}{ WU3 } & $\mathrm{w}$ \\
\hline \multicolumn{7}{|l|}{ WM1a } & $\mathrm{w}$ \\
\hline \multicolumn{7}{|l|}{ WM1b } & $\mathrm{w}$ \\
\hline \multicolumn{7}{|l|}{ WM2a } & $\mathrm{sw}$ \\
\hline \multicolumn{5}{|l|}{ WM2b } & $\mathrm{X}$ & $\mathrm{X}$ & $\mathrm{md}$ \\
\hline \multicolumn{5}{|l|}{ WM3a } & $X$ & $\mathrm{X}$ & $\mathrm{md}$ \\
\hline \multicolumn{5}{|l|}{ WM3b } & & & $\mathrm{w}$ \\
\hline \multicolumn{5}{|l|}{ WL1a } & & & $\mathrm{w}$ \\
\hline \multicolumn{5}{|l|}{ WL1b } & & & $\mathrm{w}$ \\
\hline \multicolumn{5}{|l|}{ WL2a } & & & $\mathrm{w}$ \\
\hline \multicolumn{5}{|l|}{ WL2b } & $\mathrm{X}$ & $\mathrm{X}$ & $\mathrm{md}$ \\
\hline \multicolumn{5}{|l|}{ WL3 } & $\mathrm{X}$ & $\mathrm{X}$ & $\mathrm{md}$ \\
\hline \multicolumn{5}{|l|}{ IU1 } & & & w \\
\hline \multicolumn{5}{|l|}{ IU2 } & & & $\mathrm{w}$ \\
\hline IU3a & & & & & & & w \\
\hline IU3b & & & & & & & $\mathrm{w}$ \\
\hline IU $3 c$ & & & & & & & $\mathrm{w}$ \\
\hline IU3d & & & & & & & $\mathrm{w}$ \\
\hline IU3e & & & & & & & w \\
\hline IM1a & & & & & & & $\mathrm{w}$ \\
\hline IM1b & & & & & & & $\mathrm{w}$ \\
\hline IM1c & & & & & & & $\mathrm{w}$ \\
\hline IM2a & & & & & & & $\mathrm{w}$ \\
\hline IM2b & & & & & & & $\mathrm{w}$ \\
\hline IM3a & & & & & & $\mathrm{X}$ & sw \\
\hline IM3b & & & & & & & W \\
\hline IM3c & & & & & & & $\mathrm{w}$ \\
\hline IL1a & & & & & $\mathrm{X}$ & $X$ & $\mathrm{md}$ \\
\hline IL1b & & & & & $\mathrm{X}$ & $\mathrm{X}$ & $\mathrm{md}$ \\
\hline IL1c & & & & & & & w \\
\hline IL2 & & & & & & & $\mathrm{w}$ \\
\hline IL3 & & & & & $\mathrm{X}$ & $\mathrm{X}$ & $\mathrm{md}$ \\
\hline DL1a & & & & & & $\mathrm{X}$ & sw \\
\hline DL1b & & & & & & $\mathrm{X}$ & sw \\
\hline DL1c & & & & & & & w \\
\hline DL1d & & & & & & $X$ & sw \\
\hline DLle & & & & & & $\mathrm{X}$ & sw \\
\hline DL1f & & & & & $\mathrm{X}$ & $\mathrm{X}$ & $\mathrm{md}$ \\
\hline DL2a & & & & & & & $\mathrm{w}$ \\
\hline DL2b & & & & & & & w \\
\hline DL3 & & & & & $\mathrm{X}$ & $\mathrm{X}$ & $\mathrm{md}$ \\
\hline DL4 & $X$ & & & & $\mathrm{X}$ & $X$ & $\mathrm{~d}$ \\
\hline DL5 & $X$ & & & & $\mathrm{X}$ & $X$ & $\mathrm{~d}$ \\
\hline $\mathrm{X}=\mathrm{MAI}$ & 0.34 & & & & $=\mathrm{M}$ & 0.34 or & \\
\hline $\begin{array}{l}\mathrm{w} \text { - wet } \\
\mathrm{d} \text { - severe }\end{array}$ & rought & & $\begin{array}{l}\mathrm{d}-\mathrm{dro} \\
\mathrm{md}-\mathrm{mi}\end{array}$ & ought & & w - sligh & \\
\hline
\end{tabular}




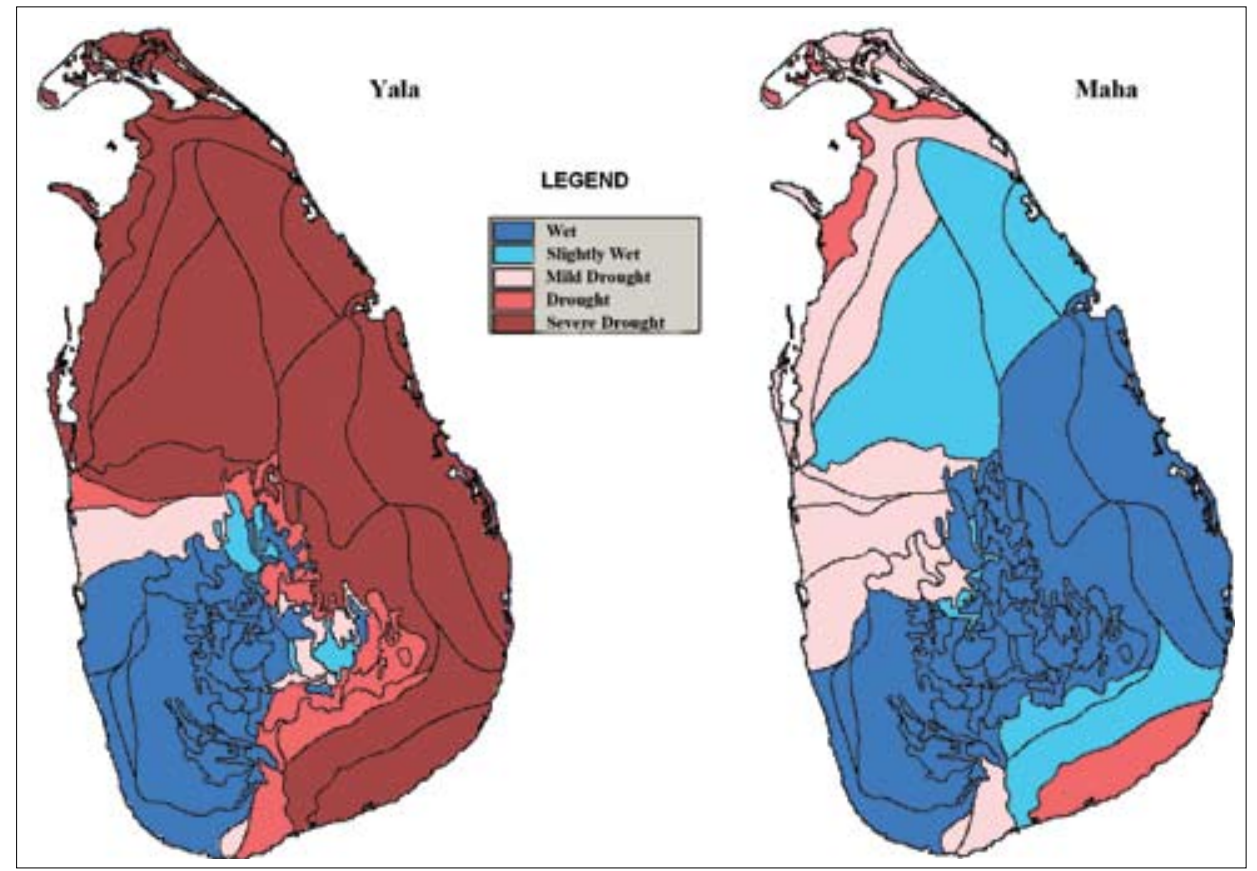

Figure 2: Spatial pattern of the drought severity during Yala and Maha seasons.

Generally, northeast monsoon rains are not so effective in the extreme northern and southern parts of the island and hence, DL4 and DL5 AERs are prone to drought conditions during Maha seasons. Meanwhile, the regions under the most effective area of northeast monsoon rains in the Dry Zone, namely, DL2a and DL2b have no threat of drought during Maha seasons and are classified as Wet. It is interesting to note that the highest tank density of the Dry Zone is found within the AERs that have slightly wet conditions during the Maha seasons. It could be speculated that sub-optimal wet conditions in these regions may carry a risk of being dry later in the season. Hence, early settlers of these regions stored excess water from the early part of the season for later use. In other AERs of the Dry Zone, either the soil type or the rainfall regime or both were not conducive to adopt such a strategy to reduce vulnerability to droughts.

\section{Spatial pattern of drought during Yala season}

The monthly distribution of water adequacy situation during Yala season is given in Table 3. Figure 2 shows the spatial pattern of the drought severity during the Yala season based on the classification given in Table 1. Out of 15 AERs in the Wet Zone, only WM3b experiences a dry month during the Yala season. This region covers a part of the Matale and Kandy districts (Figure 2). As the dry period in this region occurs during the very first month of the season, it is unlikely to affect crop production significantly due to this rainfall deficit. However, if the northeast monsoonal circulation over the island is weak during the previous two months, namely, January and February, a severe shortage in both surface and ground water may be experienced in this region.

In the case of the Intermediate Zone, the drought proneness is relatively higher compared to the wetter part of the island (Table 3). Except IL1a AER, all other AERs in the Low country Intermediate Zone are vulnerable to either drought or severe drought conditions during the Yala season (Figure 2). Being close to the effective region of the southwest monsoon, the IL1a region is likely to experience only mild drought conditions during the Yala season. However, if the southwest monsoonal circulation over the island is weak in a particular year, it may lead to intense water deficit conditions even in this region of the Low country Intermediate Zone. Under such situations, paddy cultivation under rainfed or irrigated from minor tanks in this region (i.e., Kurunegala district) is highly vulnerable to water shortage conditions during the Yala season. As the effectiveness of the southwest monsoon fades out over the Intermediate Zone, its vulnerability to drought conditions during the Yala season gradually increases. The worst situation in the Intermediate Zone is experienced in the IL3 region where rainfall during March is ineffective and, hence it falls under the category of an area prone to severe drought conditions. Meanwhile, the situation in this region is further aggravated due to presence of sandy Non Calcic Brown (NCB) soils which has a low water holding capacity. 
Out of eight AERs in the Mid country Intermediate Zone, only two AERs remained wet during the Yala season. As these two AERs namely, IM2a and IM3a are adjacent to the country's wettest AERs such as WM1b, WL2a and
WM3b, they exhibit relatively wet conditions. This is mainly attributed to the effect of southwest monsoon rains. All other AERs in the Mid country Intermediate Zone exhibited drought conditions during the Yala

Table 3: Monthly drought severity of each AER during the Yala season

\begin{tabular}{|c|c|c|c|c|c|c|c|}
\hline \multirow[t]{2}{*}{ Zone } & \multicolumn{6}{|c|}{ Yala } & \multirow{2}{*}{$\begin{array}{c}\text { Severity } \\
\text { Class }\end{array}$} \\
\hline & Mar & Apr & May & June & July & Aug & \\
\hline WU1 & & & & & & & w \\
\hline WU2a & & & & & & & w \\
\hline WU2b & & & & & & & w \\
\hline WU3 & & & & & & & $\mathrm{w}$ \\
\hline WM1a & & & & & & & $\mathrm{w}$ \\
\hline WM1b & & & & & & & w \\
\hline WM2a & & & & & & & w \\
\hline WM2b & & & & & & & $\mathrm{w}$ \\
\hline WM3a & & & & & & & w \\
\hline WM3b & $\mathrm{X}$ & & & & & & sw \\
\hline WL1a & & & & & & & $\mathrm{w}$ \\
\hline WL1b & & & & & & & w \\
\hline WL2a & & & & & & & w \\
\hline WL2b & & & & & & & w \\
\hline WL3 & & & & & & & w \\
\hline IU1 & & & & & & & w \\
\hline IU2 & & & & & & & w \\
\hline IU3a & & & & $\mathrm{X}$ & $\mathrm{X}$ & & $\mathrm{md}$ \\
\hline IU3b & & & & $X$ & $X$ & & $\mathrm{md}$ \\
\hline IU $3 \mathrm{c}$ & & & & $\mathrm{X}$ & & & sw \\
\hline IU3d & & & & $\mathrm{X}$ & & & sw \\
\hline IU3e & & & & $\mathrm{X}$ & $\mathrm{X}$ & & $\mathrm{md}$ \\
\hline IM1a & & & & $\mathrm{X}$ & $\mathrm{X}$ & & $\mathrm{md}$ \\
\hline IM1b & & & & $\mathrm{X}$ & $\mathrm{X}$ & $\mathrm{X}$ & $\mathrm{d}$ \\
\hline IM1c & & & & $X$ & $X$ & $X$ & $\mathrm{~d}$ \\
\hline IM2a & & & & & & & w \\
\hline IM2b & & & & $X$ & $X$ & $\mathrm{X}$ & $\mathrm{d}$ \\
\hline IM3a & & & & & & & w \\
\hline IM3b & $\mathrm{X}$ & & & & $\mathrm{X}$ & $\mathrm{X}$ & $\mathrm{d}$ \\
\hline IM3c & & & & $\mathrm{X}$ & $X$ & $\mathrm{X}$ & $\mathrm{d}$ \\
\hline IL1a & $\mathrm{X}$ & & & & & $\mathrm{X}$ & $\mathrm{md}$ \\
\hline IL1b & $\mathrm{X}$ & & & & $\mathrm{X}$ & $\mathrm{X}$ & $\mathrm{d}$ \\
\hline IL1c & & & & $\mathrm{X}$ & $\mathrm{X}$ & $\mathrm{X}$ & $\mathrm{d}$ \\
\hline IL2 & $\mathrm{X}$ & & & $\mathrm{X}$ & $\mathrm{X}$ & $\mathrm{X}$ & $\mathrm{sd}$ \\
\hline IL3 & $X$ & & & $\mathrm{X}$ & $\mathrm{X}$ & $\mathrm{X}$ & sd \\
\hline DL1a & & & & $\mathrm{X}$ & $X$ & $\mathrm{X}$ & $\mathrm{d}$ \\
\hline DL1b & $\mathrm{X}$ & & $\mathrm{X}$ & $\mathrm{X}$ & $\mathrm{X}$ & $\mathrm{X}$ & $\mathrm{sd}$ \\
\hline DL1c & $\mathrm{X}$ & & $\mathrm{X}$ & $\mathrm{X}$ & $\mathrm{X}$ & $\mathrm{X}$ & $\mathrm{sd}$ \\
\hline DL1d & $\mathrm{X}$ & $\mathrm{X}$ & $\mathrm{X}$ & $\mathrm{X}$ & $\mathrm{X}$ & $\mathrm{X}$ & $\mathrm{sd}$ \\
\hline DL1e & $\mathrm{X}$ & & $\mathrm{X}$ & $\mathrm{X}$ & $\mathrm{X}$ & $\mathrm{X}$ & $\mathrm{sd}$ \\
\hline DL1f & $\mathrm{X}$ & & $\mathrm{X}$ & $\mathrm{X}$ & $X$ & $\mathrm{X}$ & sd \\
\hline DL2a & $\mathrm{X}$ & & $\mathrm{X}$ & $\mathrm{X}$ & $\mathrm{X}$ & $\mathrm{X}$ & $\mathrm{sd}$ \\
\hline DL2b & $\mathrm{X}$ & $\mathrm{X}$ & $\mathrm{X}$ & $\mathrm{X}$ & $\mathrm{X}$ & $\mathrm{X}$ & $\mathrm{sd}$ \\
\hline DL3 & $X$ & & $X$ & $X$ & $X$ & $X$ & $\mathrm{sd}$ \\
\hline DL4 & $\mathrm{X}$ & & $\mathrm{X}$ & $\mathrm{X}$ & $\mathrm{X}$ & $\mathrm{X}$ & sd \\
\hline DL5 & $\mathrm{X}$ & & $\mathrm{X}$ & $\mathrm{X}$ & $\mathrm{X}$ & $\mathrm{X}$ & sd \\
\hline \multicolumn{3}{|c|}{$\mathrm{X}=\mathrm{MAI}<0.34$} & \multicolumn{5}{|c|}{ no entry $=$ MAI 0.34 or $>0.34$} \\
\hline \multicolumn{2}{|c|}{$\begin{array}{l}\text { w - wet } \\
\text { sd - severe drought }\end{array}$} & \multicolumn{3}{|c|}{$\begin{array}{l}\mathrm{d} \text { - drought } \\
\text { md - mild drought }\end{array}$} & \multicolumn{2}{|c|}{ sw - slightly wet } & \\
\hline
\end{tabular}


season except the IM1a region which has a mild drought condition during the Yala season. It is mainly attributed to the relatively high rainfall of August and September due to the formation of thunderstorms in the eastern flank of the central highlands when the southwest monsoonal circulation is weak.

Both IU1 and IU2 AERs in the Up country Intermediate Zone are less likely to experience drought hazards during Yala seasons and are classified under the Wet category. Both these AERs receive a substantial amount of rain fall during the southwest monsoon even though they do not fall directly under the most effective area of the southwest monsoon. The rest of the AERs of the Up country Intermediate Zone, namely, IU3a, IU3b, IU3c, IU3d, and IU3e have either slightly wet or mild drought conditions depending on the contribution of southwest monsoon rains to the respective regions.

All eleven AERs of the Dry zone of Sri Lanka are prone to severe drought conditions during Yala seasons irrespective of their geographical location (Table 3 $\&$ Figure 2). This is mainly attributed to the relative ineffectiveness of the first intermonsoon rains over the Dry Zone and moisture bereft flow of the southwest monsoons over most parts of the Dry zone during May to September as a Föhn like wind (Kachchan or Yal Hulang). Such winds along with clear sky conditions, which permits enormous amount of solar radiation, result in higher evapotranspiration leading to soil moisture stress in crops. Hence, drought injuries are inevitable in rainfed upland crops during Yala seasons unless supplementary irrigation is provided.

\section{CONCLUSION}

As the name implies, the Wet Zone does not exhibit droughts during Maha seasons except in the WL2b and WL3 regions which have slight vulnerability for droughts. In the Intermediate Zone, all AERs in the Up country and Mid country Intermediate Zone are generally free from drought hazards during Maha seasons. Out of five AERs of the Low country Intermediate Zone except IL2 and IL1c other three AERs are vulnerable to drought conditions during Maha seasons. In contrast to Yala seasons, almost all AERs of the Dry Zone are less likely to experience drought conditions during Maha seasons except those located in the extreme northwestern and southeastern regions.
There is a slim chance of drought conditions occurring in the entire Wet Zone during Yala seasons. In the Intermediate Zone, the drought proneness is relatively higher compared to the wetter part of the island. All AERs in the Low country Intermediate Zone are vulnerable to drought conditions of varying degrees during the Yala season except the IL1a region. Excluding the AERs that adjoin the high rainfall receiving AERs of the Wet Zone, all other AERs of the Mid country Intermediate zone are also prone to drought conditions during Yala seasons. In contrast, almost all AERs of the Up country Intermediate Zone are less likely to experience drought conditions during Yala seasons. All the AERs of the Dry Zone are highly vulnerable to drought conditions during Yala seasons.

\section{Acknowledgement}

The authors thank Mrs. U. K. Wijekoon, Programme Assistant, Natural Resources Management Centre, Peradeniya for processing relevant agro-meteorological data.

\section{References}

1. Wood S. \& Pardey P.G. (1998). Agro-ecological aspects and evaluating agricultural research and development. Agricultural Systems 57(1):13-42.

2. Panabokke C.R. (1996). Soils and Agro-ecological environments of Sri Lanka. Natural Resources Series No 2. Natural Resources, Energy and Science Authority, 47/5, Maitland Place, Colombo 7.

3. Siriweera W.I. (1987). Floods, droughts, famines in pre-colonial Sri Lanka. Modern Sri Lanka studies 2(1 \& 2):79-88.

4. Hargreaves G.H. (1972). The evaluation of water deficiencies. Age of Change Priorities for Land and Water, Irrigation and Drainage Specialty Conference, American Society of Civil Engineers 273-290.

5. Hargreaves G.H. (1975). Moisture Availability and Crop Production. Transactions of the ASAE 18(5): 980-984.

6. Punyawardena B.V.R., Bandara T.M.J., Munasinghe M.A.K., Banda N.J. \& Pushpakumara S.M.V. (2003). Agro-ecological Regions of Sri Lanka. Natural Resources Management Center, Department of Agriculture, Peradeniya.

7. Munasinghe M.A.K.\& Chithranayana R.D.(2004). Spatiotemporal variability of potential evapotranspiration in Sri Lanka and its application in agricultural planning. Journal of the Soil Science Society of Sri Lanka 16: 29-42. 